\title{
Integrated of Blended Learning System (BLs) and Knowledge Management System
}

\author{
Walid Qassim Qwaider \\ Majmaah University,College of Science and Humanities in Ghat \\ Management Information Systems Department, Saudi Arabia
}

\begin{abstract}
This study is exploring the role of Blended e-learning system in knowledge management. Online education has already been accepted as the way of the future, knowledge may be distributed across both time and space. Knowledge management techniques can be used to capture, organize and deliver this knowledge and management systems can be used to quickly identify the most relevant information and distribute it to meet specific needs. This paper, on the basic concepts of $B L s$ and knowledge management $A$ discussion on BLs and knowledge management system are defined and capabilities for their better integration Introduction and leveraged for effective online education and training is presented.
\end{abstract}

\section{Introduction}

Blended e-Learning system (BLs) consists of the combination of e-Learning and traditional education approach. BLs combines online learning with face-to-face learning. The goal of BLs is to provide the most efficient and effective learning experience by combining different learning environments. BeL stands in the forefront in respect of interactivity with target learner group, integration of technology and enriching learning process into education [1], [4]. BLs has been described as learning 'that is facilitated by the effective combination of different modes of delivery, models of
Teaching and styles of learning, and founded on transparent communication amongst all parties involved with a course [6]. However recent research reveals great interest to introduce Knowledge Management system (KMS) ideas to BLs. [15]. The joint studies of BLs and KMS point out the same fundamental goal: facilitating organizational learning. Researchers try to analyze the similarity of the goals, methods of assessment, and some knowledge sharing processes both in BLs and KM. An BLs within KM is traditionally analyzed as a knowledge resource repository, where the KM methods can be implemented to increase the effectiveness of knowledge dissemination [17]. The research about "how can integrated between BLs and Knowledge management system?" otherwise this study are discussed which benefit and more effective integration of BLs and knowledge management capabilities delivery and powerful use of learning materials and activities in the process of knowledge manipulation and exchange in institution in order to provide organizational success and prosperity

\section{Knowledge Management system and BLs}

\subsection{Knowledge Management KM}

The concept of $\mathrm{KM}$ is encompassing any processes and practices concerned with the creation, acquisition, capture, sharing and use of knowledge, skills and expertise. $\mathrm{KM}$ is the discipline that helps spread knowledge of individuals or groups across organizations in ways that directly affect performance. KM getting the right information within the right context, person, and time for the right business purposes. Otherwise Spreading knowledge of individual or groups 
is basically the KM activity that involves generation, codifications and transfer [7].

$\mathrm{KM}$ is interested with the identification, acquisition, distribution and maintenance of substantial and relevant knowledge. Rowley describes the term Knowledge Management as follows: "Knowledge management is concerned with the exploitation and development of the knowledge assets of an organization with a view to furthering the organization's objectives [12]. Drucker that concerned the term "knowledge society system " and began the discussion of the idea of managing knowledge in organizations. He claimed that knowledge would become increasingly social in nature [8].

\subsection{Knowledge Management system KMS}

The KMS definition is a concept that can be used for creating knowledge repositories, improving knowledge access and sharing as well as communicating through collaboration and managing knowledge as an asset in learning organization [16].

KMS are special type of information systems that supports activities related to the acquisition, generation, codification, storage, transfer, retrieval, and use of knowledge within organizations. The idea of a KMS is to enable employees of an organization to have access to the company's knowledge of facts, sources of information, and solutions. Having employees share their knowledge could potentially lead to more effective problem solving and it could also lead to ideas for new or improved products and services [19].

The goal of a KMS is to get the right information to the right people at the right time. This will increase efficiency leading to a competitive advantage. In other words, KMS are meant to support knowledge processes. These KM systems have been deployed in many organizations with the hope that they will have a positive effect on performance [2].

\subsection{Knowledge conversion (SECI) spiral model}

Nonaka and Takeuchi [14] spiral model explain how knowledge is created and transferred in an organization through interactions between tacit and explicit knowledge. More specifically they recognize these interactions as 'knowledge conversion'. There are four modes of knowledge socialization, externalization, conversion, namely, combination and internalization see Figure 1 summarized in the following:

- Socialization (from tacit to tacit): where knowledge transfer takes place in a tacit form. Here, an individual acquires tacit knowledge directly from others through shared experience, observation, imitation and so on.

- Externalization (from tacit to explicit): through articulation of tacit knowledge into explicit concepts. This field prompted by meaningful dialogues or reflections.

- Combination (from explicit to explicit): through a systematization of concepts drawing on different bodies of explicit knowledge present in the environment of an organization.

- Internalization (from explicit to tacit): through a process of "learning by doing" and through a verbalization and documentation of experiences.

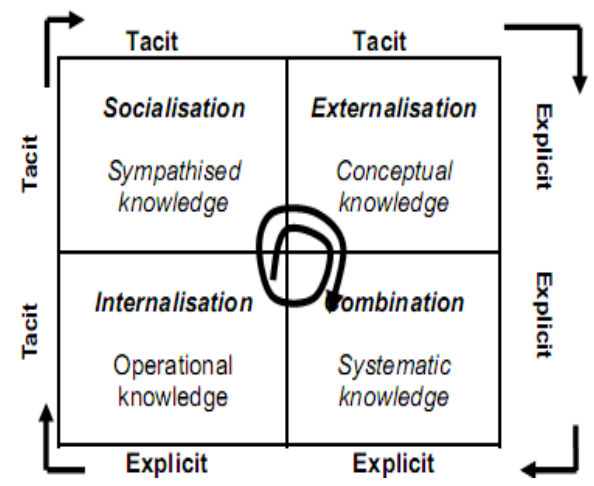

Figure 1. SECI diagram representing four modes of Knowledge conversions

(Source: Nonaka and Takeuchi, 1995)

The main benefit of this model is that it provides a mechanism to provide an understanding on the epistemology and dynamism of knowledge itself, and provides a framework for management of the relevant knowledge management processes from the ontological perspective [11]. We will use this framework to discuss how knowledge is shared and generated and learning take place in virtual communities of practice concept (CoP).

\section{Blended e-Learning systems (BLs)}

Education is one of the sectors that most important from the current technological advancement. The concept of distance learning has been revolutionized to what is now known as e-learning or Web-based learning programs. However, it has been observed that the first generation of e-learning programs focused on presenting physical classroom-based instructional content over the internet with 
very little attention given to the peculiar nature of this delivery program in comparison to the tradition classroom lesson [20]. As well as, this definition is limiting and does not indicate the range of possibilities that blended learning can offer or indeed the pedagogical decisions that inform a blended e-learning offer [3]. However BLs is more than the combination of e-learning with F2F modes of delivery, how can it then be defined in a way that indicates the educational process and decisions that inform and shape a blended e-learning approach and the subsequent skills and support needed to realize [3].

Blended learning "mixes various eventbased activities, including face-to-face classrooms, live e-learning, and self-paced learning. This often is a mix of traditional instructor-led training, synchronous online conferencing or training, asynchronous selfpaced study" [20].

Reflects that blended e-learning "is the combination of instruction from two historically separate models of teaching and learning: Traditional learning systems and distributed learning systems. It emphasizes the central role of computer-based technologies in blended learning."

Figure 2 shows BLs as combination learning with the Basic Support for Cooperative Work BSCW and face-to-face learning. The BSCW includes both networkbased (online learning, Internet-based learning, and Web-based learning) and non-networkbased learning (computer-based learning).

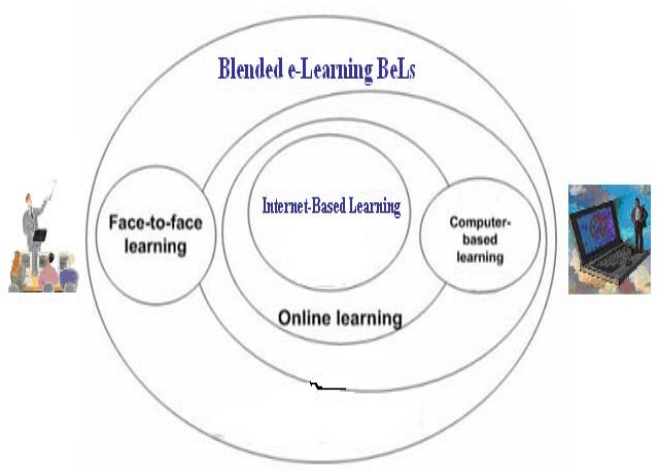

Figure 2. Competencies OF BLs

BLs contain various event-based activities, including face-to-face learning, e-learning, and self-paced learning activities. Blended learning often occurs as a mixture of traditional instructor-led training, synchronous online training, asynchronous self-paced study, and structured task based training from a teacher or mentor. The aim of blended learning is to combine the best of classroom face-toface learning experiences with the best of online learning experiences. Overall, blended learning refers to the integration of elearning tools and techniques with traditional face-to-face teaching delivery methods [1], [4]. The two important factors here are the time spent on online activities and the amount of technology utilized, see Concept of Blended Learning figure 3 below:

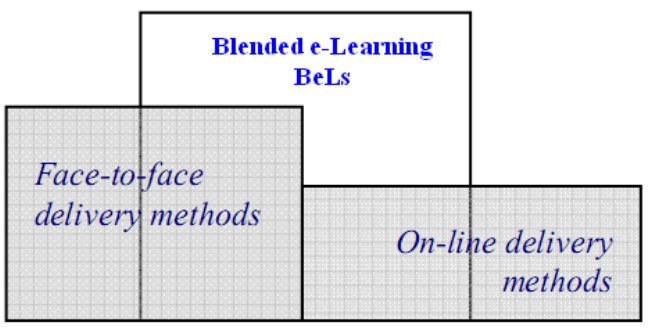

Figure 3. Defining the BLs

BLs has more meaning than showing a web page during a lesson in the classroom and using information immediately in the web page to explain the lesson. BLs is a learning of environment which combines environments of face to face learning and web-based distance learning.

Arily functions as a replacement for extension of face-to face environments. For instance, it might be used to foster learning communities, extend training events, offer follow-up resources in a community of practice, access guest experts, provide timely mentoring or coaching, present online lab or simulation activities, and deliver prework or supplemental course materials. While such uses may be unique and engaging, they are not exactly novel [1], [5].

\section{Integration of BLs and KMS}

The information technology and the Web is contribution concerning shared knowledge and the social life of learning. BLs and KMS was the social nature of constructing knowledge. He proposed the idea that people construct knowledge or understand the world through their interactions and experiences. also the concept of social knowledge and looked at learning as a social and situated process [10].

Knowledge management system KMS takes an organizational perspective on learning, and the problem lies in the lack of sharing knowledge among members of the organization. In such instances, BeL is the best way to help acquire the dynamic, distributed, shared and collaborative knowledge through the technological means 
to support this construction process. Huang explain that technology could not create the gains hoped for in the enterprise environment until system designers recognized that information is dynamic, situated and socially constructed. Enterprise knowledge must be negotiated and collectively constructed [10].

\section{Similarity between BLs and KMS}

Knowledge management is a core part of teams training so capturing of knowledge process is very similar to the processes related to selection of most appropriate learning content in BLs. Outcome of effective learning process should be not only knowing facts for a separate subject but having practical skills and developing competency in the given domain so acquiring knowledge is more precise definition of the learning outcomes instead of learning facts for different related to domain topics. Also desired outcome of learning should be knowledge acquisition and in combination with some practical skills gained in the process of education they have to present some type of competence. On this way communication and collaboration will be improved and free exchange of competencies will be provided [17].

\section{Common Characteristics of BLs and KMS}

There are many common features characteristic shared between BLs and KMS. Yordanova explain common characteristic are defined in the process of BLs and KMS: (collaboration, project development, Help desk, Learning Objects (LOs) use for presentation of learning content and knowledge, and Content Management systems (CMS)) [21]. Some of these are:

Virtual collaboration/synchronous: are one of the most important characteristics of successful education and team work include (synchronous and asynchronous) communication and different tools related to work in groups or different types of virtual communities. In education students and teachers have to exchange information related to learning activities or specific topics of the proposed learning content. Participant in education involved in different types of groups have to exchange knowledge, skills and competences. Team members in an organization or institution have to send and receive important information or data related to their duties. Free exchange of knowledge and data and capabilities for collaborative editing of documents become even more critical when different members of the team are at distance (different offices, cities or countries).

Project development: tools and capabilities is critical for execution of different team and individual tasks and delivery of necessary data, information and document in time. As well as tools is very benefit in the process of education. It allows projects developed by students to be scheduled and implemented on time. Another advantage of their integration in education is students get used to work with the tools and they know which are strong points and drawback of project management tolls implementation in their work.

Content as Learning Objects (LOs): seem to be very appropriate technology for development and exchange of different types of information. Learning Objects are discrete chunks of reusable online learning materials. A LOs or knowledge element as it is sometimes called can be a text document, an element of animation, a streaming video, audio or other form of online content. Creating central repositories of reusable learning objects using object oriented design and metadata and following the international standards for it, is serving the needs of both e-learning and knowledge management. As well as raises the quality and effectiveness of education and work.

On the base of vision of e-learning proposed by Nichani and the concept of KM defined by Nonaka and Takeuchi [14], common characteristics of both fields are described as it is shown on Figure 4.

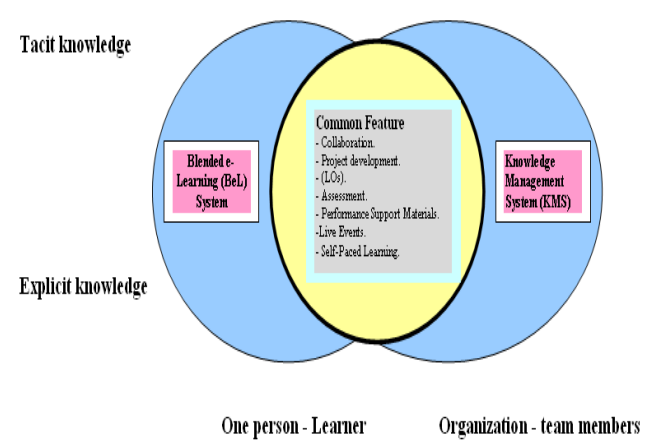

Figure 4. BLs and KM common features in context of explicit and tacit knowledge exchange

Aytac added key ingredients emerge as important elements of a blended e-learning process shown on [1]. 
Assessment: A measure of learners' knowledge. Pre-assessments can come before live or self-paced events, to determine prior knowledge, and postassessments can occur following live or self-paced learning events, to measure learning transfer.

Performance Support Materials: On-thejob reference materials that enhance learning retention and transfer, including PDA downloads, and printable references, summaries, and job aids.

Live Events (face-to-face): Synchronous, instructor-led learning events in which all learners participate at the same time, such as in a live "virtual classroom."

Self-Paced Learning: Learning experiences that the learner completes individually, at his own speed and on his own time, such as interactive, Internet-based or CD-ROM training.

\section{BLs built upon KMS methods and models}

Knowledge management tools and technologies can be applied to BLs in several ways. Via portal customized information can be aggregated and integrated within a particular working environment, application or service, or use a single interface to target an individual (face to face) user needs and interests. The following areas of BLs in which knowledge management can be most effectively used have been identified [17], [18].

\subsection{Collaborative Learning and communities of practice}

Collaborative learning involves students working together in some way to support the learning activity. They can do this by accessing a common set of learning material or by posting their own queries, observations or comments on the site. The collaboration can be between two individuals (face to face) or between larger groups of learners. It can be built on the experience of knowledge management system with communities of practice.

\subsection{Dynamic delivery and presentation of the content}

The portal can contain a repository of content that is modularized and arranged to facilitate access to it by the content developers. We set forward a dynamic generation of LO's or course modules customized to the learner group on point of content and customized on point of presentation, fitting the preferences or characteristics of the individual learner and the used appliances by them.

\section{Benefits of integration}

The people need to learn more, more often, and technology offers a broader, more confusing, palette of options, it makes intuitive sense to the researchers that knowledge management and BLs should work more closely together. Both fields aim to apply corporate know-how to meeting business objectives, and it seems absurd that managers are unable to make seamless trade-offs between the two:

- Businesses that train their people better have less need for knowledge management. Those with effective knowledge management need less training.

- When employees search a knowledge source, they'd be open to relevant BLs solutions as well. When they look for training, they might be helped by relevant knowledge management system content as well.

- When a business captures expertise, it should be able to make an even-handed decision between putting it in the knowledge management system and creating BLs (or both).

If the two approaches were used more closely together this ought to provide a more flexible set of options to meet organizations' learning needs, each might be able to address some of the weaknesses of the other, and using them together should reduce wasted investment in learning.

\section{Conclusion}

This paper focuses on basic characteristics of BLs and knowledge management system and main task of the research is to find common features of both domains. On the other hand KMS is very important part of each BLs so both domains of science influence each other very intensively. Basic processes and BLs components are discussed and their 
common features are investigated. Transfer between tacit and explicit knowledge in both directions and its support by BLs and KMS is described. Common characteristics of BLs and $\mathrm{KM}$ and are defined on the base of conducted review. The use of BeL and KMS in will definitely impact the quality of the education that is delivered and deliverability of information in a manner of knowledge and information sharing.

\section{References}

[1] Aytac. T," The influence of blending model on developing Leadership Skills of School Administrator" conference, - Applied Computing, special Issue on ICIT 2009.

[2] Abdullah R., Selamat M. H, Jaafar A, Abdullah S., \& Sura S.," An Empirical Study of Knowledge Management System Implementation in Public Higher Learning Institution", IJCSNS International Journal of Computer Science and Network Security, VOL.8 No.1, January 2008.

[3] Adams J., Blenkharn A., Briggs G. et al.,"Report to the Learning, Teaching and Assessment Committee of the Blended Learning Task and Finish Group Faculty of Health and Human Sciences, March, 2006.

[4] Banadosa, E., Blended-learning Pedagogical Model for Teaching and Learning EFL Successfully Through an Online Interactive Multimedia Environment, CALICO Journal, Vol. 23, No. 3, p-p 533-550, (2006).

[5] Bonk, C. J. \& Graham, C. R., (Eds.). "Future Directions of Blended Learning In Higher Education and Workplace Learning Settings" Handbook of blended learning: Global Perspectives, local designs. San Francisco, CA: Pfeiffer Publishing. (2004).

[6] Draffan E. A. \& Rainger. P, "A model for the identification of challenges to blended learning", SSN 0968-7769, 2006.

[7] Davenport, T. H. and Prusak, L, "Information Ecology: Mastering the Information and Knowledge Environment", Oxford University Press: New York, (1997).

[8] Drucker, P. F, "The age of social transformation", The Atlantic Monthly, 274(5), 53-80, (1994).
[9] Denning S., “The Springboard: How Storytelling Ignites Action In Knowledge-Era Organizations”, Boston, Butterworth Heinemann, 2000.

[10] Huang, K., "E-Learning 2.0 for Knowledge Management in Enterprises", Ninth Annual IBER \& TLC Conference Proceedings 2009.

[11] Hafeez, K. and Alghatas, F., "Knowledge Management in a Virtual Community of Practice using Discourse Analysis", Electronic Journal of Knowledge Management Volume 5 Issue 12007 (29 - 42).

[12] Rowley J., "From Learning Organization to Knowledge Entrepreneur", Journal of Knowledge Management, Vol. 4, No. 1, pp 714, 2000.

[13] Nichani, M., LCMS = LMS + CMS [RLOs]. www.elearningpost.com/articles/ archives/lcms_lms_cms_rlos/.

[14] Nonaka, I., Takeuchi, H., The knowldgecreating company: How Japanese companies create the dynamics of innovation, New york, Oxford university press, 1995.

[15] Ravet S., “eLearning and Knowledge Management", The Newsletter of the PROMETEUS Network N20, pp 2-6, JulyAugust 2002. Available at http://prometeus.org/news/PROMETEUS_Ne wsletter20.pdf.

[16] Rusli A., Shamsul S., Alias R. \& Selamat M.," Collaborative Knowledge Management System for Learning Organizations". Journal of Information \& Knowledge Management, 4(4). pp: 1 -9. (2005).

[17] Sammour G., Schreurs J., Abdullah Y. Z., Vanhoof K.," Knowledge Management and eLearning in Professional Development", Hasselt University, Diepenbeek, Belgium, 2004.

[18] Spector, M. J. and Edmonds, G. S, "Knowledge Management in Instructional Design", ERIC Digest, September 2002.

[19] Tiwana A., "The Knowledge Management Toolkit. Prentice Hall: New Jersey, (2000).

[20] Singh H., "Building Effective Blended Learning Programs", Educational Technology, 43(6), 51-54. (2003). 
International Journal for e-Learning Security (IJeLS), Volume 1, Issues 2, September 2011

[21] Yordanova, K.," Integration of Knowledge management and E-learning common features", International Conference on Computer Systems and Technologies CompSysTech, 2007. 